UC46

U5t

no. $98 / 16$

US Army Corps

of Engineers

Construction Engineering

Research Laboratories
USACERL Technical Report 98/16

December 1997

\title{
Evaluation of Automatic Aqueous Parts Washers
}

by

Michelle J. Hanson

Teresa S. Aden

Susan J. Bevelheimer

In the past, solvents have been used to clean oils and greases, soils, inorganic salts, and foreign particles from manufactured materials or parts. However, increased awareness of the health, safety, and environmental issues surrounding the use and disposal of solvents has stimulated a search for alternatives. Many parts cleaning practices that once relied on petroleum-based solvents can also be done with aqueous cleaning. Petroleum-based solvents depend largely on their abilities to dissolve organic contaminants, while aqueous

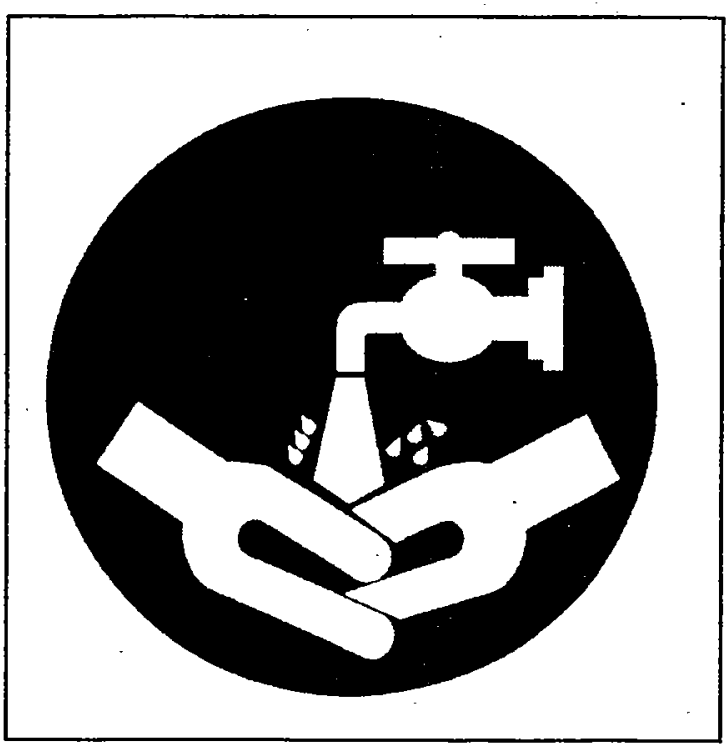

cleaning uses water as the primary solvent and a combination of water conditioners, detergents, and surfactants to promote better cleaning of the metal object. This research evaluated automatic aqueous parts washers, sometimes called "jet washers," currently in use at U.S. Army installations. The study found that users'are generally satisfied with the performance of these washers and that the washers are relatively low maintenance. Recommendations were made to optimize the use of automatic aqueous parts washers. 


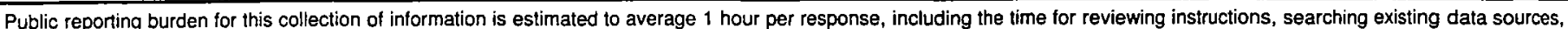

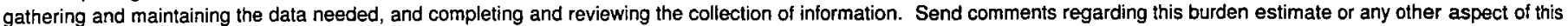

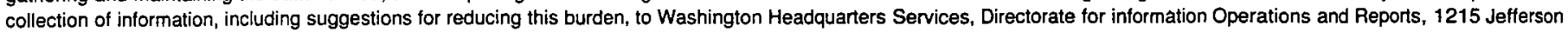
Davis Highway, Suite 1204, Arlington, VA 22202-4302, and to the Office of Management and Budget, Paperwork Reduction Project (0704-0188), Washington, DC 20503.

\begin{tabular}{|l|l|l|}
\hline 1. AGENCY USE ONLY (Leave Blank) & $\begin{array}{c}\text { 2. REPORT DATE } \\
\text { December } 1997\end{array}$ & $\begin{array}{c}\text { 3. REPORT TYPE AND DATES COVERED } \\
\text { Final }\end{array}$ \\
\hline
\end{tabular}

4. TITLE AND SUBTITLE
Evaluation of Automatic Aqueous Parts Washers

5. FUNDING NUMBERS MIPR

6. AUTHOR(S)
Michelle J. Hanson, Teresa S. Aden, and Susan J. Bevelheimer

7. PERFORMING ORGANIZATION NAME(S) AND ADDRESS(ES)

U.S. Army Construction Engineering Research Laboratories (USACERL)

P.O. Box 9005

Champaign, IL 61826-9005

W26H8F62700906

9. SPONSORING / MONITORING AGENCY NAME(S) AND ADDRESS(ES)

U.S. Army Center for Public Works (USACPW)

ATTN: CECPW-ES

7701 Telegraph Road

Alexandria, Va 22312-3862

11. SUPPLEMENTARY NOTES

Copies are available from the National Technical Information Service, 5285 Port Royal Road, Springfield, VA 22161.

12a. DISTRIBUTION / AVAILABILITY STATEMENT

12b. DISTRIBUTION CODE

Approved for public release; distribution is unlimited.

13. ABSTRACT (Maximum 200 words)

In the past, solvents have been used to clean oils and greases, soils, inorganic salts, and foreign particles from manufactured materials or parts. However, increased awareness of the health, safety, and environmental issues surrounding the use and disposal of solvents has stimulated a search for alternatives. Many parts cleaning practices that once relied on petroleum-based solvents can also be done with aqueous cleaning. Petroleum-based solvents depend largely on their abilities to dissolve organic contaminants, while aqueous cleaning uses water as the primary solvent and a combination of water conditioners, detergents, and surfactants to promote better cleaning of the metal object. This research evaluated automatic aqueous parts washers, sometimes called "jet washers," currently in use at U.S. Army installations. The study found that users are generally satisfied with the performance of these washers and that the washers are relatively low maintenance. Recommendations were made to optimize the use of automatic aqueous parts washers.

\begin{tabular}{|c|c|c|}
\hline $\begin{array}{l}\text { 14. SUBNECT TERMS } \\
\text { vehicles } \\
\text { operation and maintenance } \\
\text { aqueous cleaning }\end{array}$ & \multicolumn{2}{|c|}{ military installations } \\
\hline $\begin{array}{l}\text { 17. SECURITY CLASSIFICATION } \\
\text { OF REPORT } \\
\text { Unclassified }\end{array}$ & $\begin{array}{l}\text { 18. SECURITY CLASSIFICATION } \\
\text { OF THIS PAGE } \\
\text { Unclassified }\end{array}$ & $\begin{array}{l}\text { 19. SECURITY CLASSIFICATION } \\
\text { OF ABSTRACT } \\
\text { Unclassified }\end{array}$ \\
\hline
\end{tabular}

8. PERFORMING ORGANIZATION

TR $98 / 16$

0. SPONSORING / MONITORING AGENCY REPORT NUMBER 


\section{Foreword}

This study was conducted for the U.S. Army Center for Public Works (USACPW), under Military Interdepartmental Purchase Request (MIPR) No. W26H8F62700906; Work Unit G96, "Evaluation of Automatic Aqueous Parts Washers.” The technical monitor was Cris Sawyer, CECPW-ES.

The work was performed by the Troop Installation Operation Division (UL-T) of the Utilities and Industrial Operations Laboratory (UL), U.S. Army Construction Engineering Research Laboratories (USACERL). The USACERL principal investigator was Michelle J. Hanson. Walter J. Mikucki is Chief, CECER-UL-T; John T. Bandy is Operations Chief, CECER-UL; and Gary W. Schanche, CECER-UL, is the responsible Technical Director. The USACERL technical editor was William J. Wolfe, Technical Resources.

COL James A. Walter is Commander and Dr. Michael J. O'Connor is Director of USACERL. 


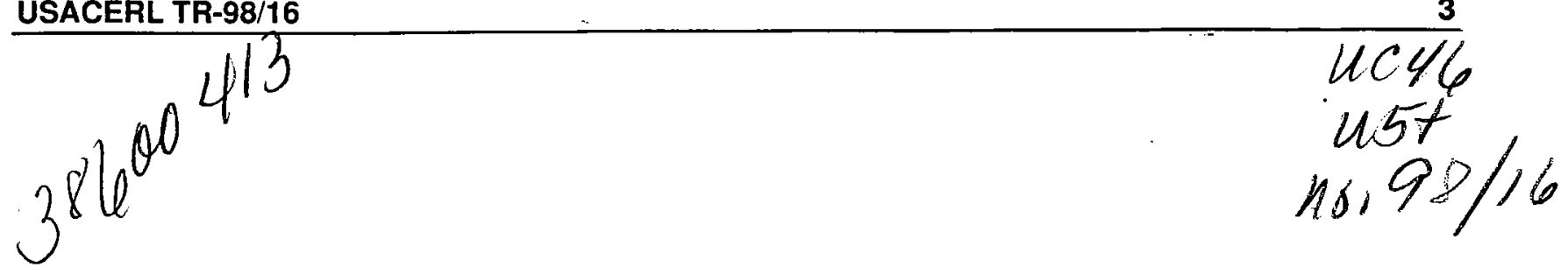

\section{Contents}

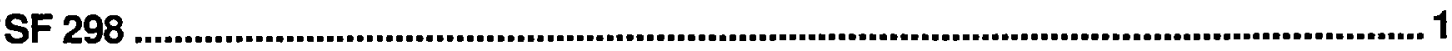

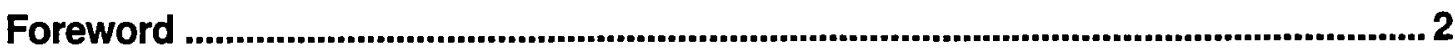

1 Introduction .............................................................................................................. 5

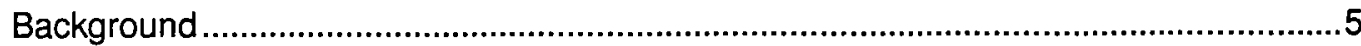

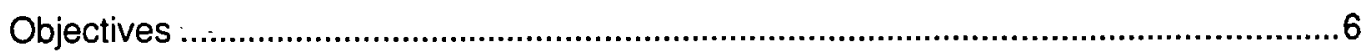

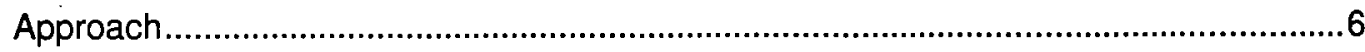

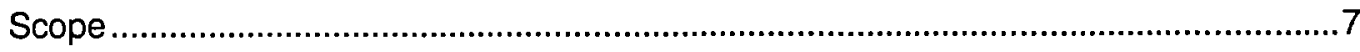

2 Description of Equipment .......................................................................................... 8

$3 \quad$ Cleaning Effectiveness......................................................................................10

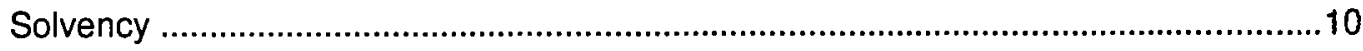

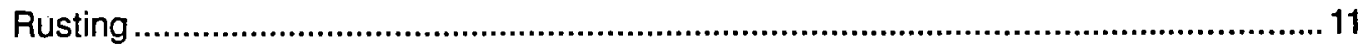

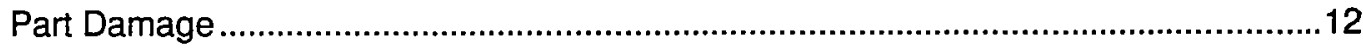

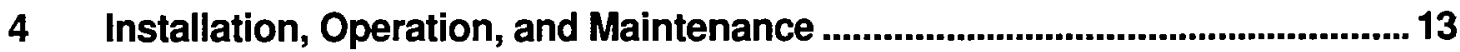

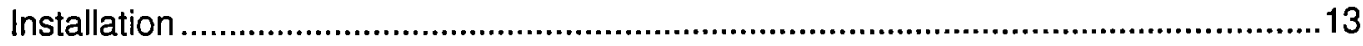

Operation and Maintenance :.................................................................................13

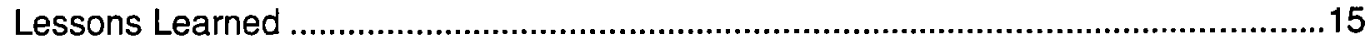

$5 \quad$ Environmental Concerns .........................................................................................17

6 Conclusions and Recommendations .................................................................. 20

References ................................................................................................................................... 22

Appendix A: Automatic Parts Washer Manufacturers ..............................................23

Appendix B: Sample Analyses of Parts Washer Waste Streams.............................. 25

Distribution 


\section{Introduction}

\section{Background}

In the military, it is essential to maintain vehicle and equipment readiness. Parts cleaning is a necessary procedure in equipment maintenance and repair. This activity occurs at all levels of Army vehicle maintenance. In the past, solvents have been used to clean oils and greases, soils, inorganic salts, and foreign particles from manufactured materials or parts. Methylene chloride, perchloroethylene (PCE), trichloroethylene (TCE), and 1,1,1-trichloroethane (TCA) have been the traditional chlorinated degreasing solvents used in cleaning processes due to their physical and chemical properties. However, increased awareness of the health, safety, and environmental issues surrounding the use and disposal of solvents has stimulated a search for alternatives.

Many parts cleaning practices that once relied on petroleum-based solvents can also being done with aqueous cleaning. Aqueous parts washers are often promoted as a pollution prevention alternative to traditional petroleum-based solvent parts washers. Aqueous parts washers have been used for decades to meet cleaning needs in the manufacturing environment, and they are rapidly replacing solvent cleaning systems and steam cleaners for out-of-frame cleaning of large parts and engines.

Regulations governing the use of chlorinated degreasing solvents and the degreasing process have been a major driver in promoting the application of alternative cleaners and cleaning systems for degreasing. Among the most recent regulations for chlorinated degreasing solvents is the National Emissions Standards for Hazardous Air Pollutants (NESHAP) promulgated in the Clean Air Act. The NESHAP, finalized by the U.S. Environmental Protection Agency (USEPA) in November 1994 and set to go into full effect in December 1997, sets maximum achievable control technology (MACT) standards for owners and operators of halogenated solvent cleaning machines. The MACT standards cover batch vapor solvent cleaning machines and in-line solvent cleaning machines, and are designed to regulate the emissions of methylene chloride, perchloroethylene, trichloroethylene, carbon tetrachloride, and chloroform (Menke et al. 1995). Under the NESHAP, users will be allowed to clean parts 
with these nonozone-depleting solvents as long as emissions are less than allowable limits (Koelsch 1995).

The USEPA has established a deadline for the elimination of several solvent alternatives because they are considered hazardous air pollutants, because they are considered ozone depleting, and because they present safety concerns such as flammability or toxicity to humans (Adams 1997). As of 1 January 1996, the toughened Clean Air Act banned production of industry's two most popular cleaning solvents, CFC-113 and 1,1,1-trichloroethane (methyl chloroform), and will prohibit their use after 1 January 2003 (Koelsch 1995).

Unlike petroleum-based solvents, which depend largely on their ability to dissolve organic contaminants, aqueous cleaning uses a combination of physical and chemical properties to displace soil from a substrate (Menke et al. 1995). Aqueous cleaning solutions use water as the primary solvent. A combination of water conditioners, detergents, and surfactants are added to promote better cleaning of the metal object. In addition, special additives such as builders, $\mathrm{pH}$ buffers, inhibitors, saponifiers, emulsifiers, and deflocculants can be added to meet the desired cleaning requirements (Ohio EPA 1993).

\section{Objectives}

The objective of this research was to evaluate automatic aqueous parts washers, sometimes called "jet washers," currently in use at U.S. Army installations.

\section{Approach}

1. Researchers reviewed available literature pertaining to automatic parts washer technology. Information from this review was then compiled and summarized. Of particular interest was a report summarizing findings from laboratory studies on solvent alternatives performed by the U.S. Army Tank Automotive RDE Center, at the Mobility Technology Center, at Fort Belvoir, VA. Results from this laboratory analysis are compared with U.S. Army Construction Engineering Research Laboratories (USACERL) field data findings throughout this report.

2. After completing the literature search, researchers evaluated existing operational experience by collecting data such as cleaning effectiveness, operations and maintenance (O\&M) problems, equipment purchase and 
start-up costs, labor savings, and environmental costs such as hazardous material handling and hazardous waste disposal. This information was gathered in two different ways:

a. A survey was developed that contained questions pertaining to the use and upkeep of automatic parts washers. This survey was faxed to Directorate of Public Works (DPW) Environmental Offices at Army installations across the country.

b. Site visits were conducted by USACERL researchers. During these visits, both personnel at the DPW Environmental Office and maintenance personnel (those operating the washers) were interviewed.

3. A total of 18 installations were queried regarding use of automatic parts washers. Three of these installations had no parts washers on post. Two installations did not respond. One installation provided brief information in a telephone interview. Of the remaining 12 installations, five were visited by USACERL researchers and seven provided input via written surveys.

\section{Scope}

Only those washers that use high pressure and hot water in addition to the aqueous cleaner were evaluated. Other types of aqueous-based parts washers were beyond the scope of this study. 


\section{Description of Equipment}

Automatic aqueous parts washers rely on both chemical and physical properties to clean automotive and equipment parts. They act much like a dishwashers, although sometimes much larger in size. Dirty parts are usually placed in a large steel, mesh basket, or turntable (both are referred to in this report as the "turntable"). For placing large, heavy items on a turntable, parts washers can be equipped with a loading boom. The turntable is mechanically rotated while a stationary spray nozzle manifold provides 360-degree spray coverage. As the turntable rotates, the parts are washed from all angles with a hot (140 to 200 ${ }^{\circ} \mathrm{F}$ ) biodegradable detergent and water solution at a rate that can vary from 50 to 250 gallons per minute (gpm).

The mechanical agitation of the parts provided by the rotating turntable, the force of the spray jets, the heat, and the detergent combine to strip oil, grease, carbon, etc., from the parts. The spray manifold can be manipulated and custom-jetted to provide the best angle of impact for the type of parts being cleaned. For example, some manufacturers provide special fixtures that screw into the manifold to clean aircraft wheels.

Access to the turntable is usually provided either through a top-loading, hinged door (manual or hydraulic), common on smaller units, or through a side access door that swings wide horizontally, common on larger units. With the sideopening access, the turntable usually travels on a heavy duty carriage that allows the turntable to be pulled out for easier loading. The turntable can also be pulled out onto the floor for loading.

All units are self-contained; the washers are closed loop. The washwater (or rinsewater) is recycled. Enhancements such as filter bags are often used to improve water quality between cleanouts. There is no discharge while washing with a parts washer until the unit must be completely cleaned and the water replaced. Oil and grease are removed from the cleaning solution via an oil

\footnotetext{
${ }^{\star}{ }^{\circ} \mathrm{F}=\left({ }^{\circ} \mathrm{C} \times 1.8\right)+32 ; 1 \mathrm{gal}=3.78 \mathrm{~L}$
} 
skimmer apparatus. Oil is channeled to an outside holding container for collection later removal.

The standard power source requirements usually range from 120 to $220 \mathrm{~V}$, singlephase, for smaller units. Facilities wired for supplying the standard 208V may encounter problems with the larger units, which may require at least a $220 \mathrm{~V}$, three-phase supply. The larger units usually have motors or drives rated at $230 \mathrm{~V}$.

Most units have optional available features. Automatic controls such as timers or water feeds free up operator's time. A fresh water rinse cycle is an option most manufacturers offer. The rinse cycle option would be needed, for example, to meet the cleanliness standard for parts for Non-Destructive Inspection (NDI), which requires that no residue remain on the parts after washing.

Equipment at selected Army. installations for which USACERL researchers obtained data was typically used in automotive applications: cleaning engine blocks, cranks, heads, carburetors, transmission parts, wheel bearings, etc. Tank size of the machines ranged from 75 to almost 600 gal and the weight capacity of the baskets or turntables range from 200 to $5000 \mathrm{lb}$.

Appendix A includes a list of manufacturer's of automatic parts washers. This list is not meant to be inclusive, nor should a manufacturer's appearance in the list be considered a product endorsement.

${ }^{*} \mathrm{lb}=0.454 \mathrm{~kg}$. 


\section{Cleaning Effectiveness}

Perhaps the most important aspect to evaluate when considering solvent substitutes is how effective the alternative process is at cleaning the parts. Vehicle and equipment parts must be clean so that they can be inspected, repaired, or replaced. These parts usually contain large quantities of oils, grease, soil, and/or carbon deposits, which must be removed without adversely affecting the parts. An alternative that does not adequately clean, or one that damages parts during the cleaning process, is unacceptable.

\section{Solvency}

Aqueous cleaning solutions are much more limited in their ability to remove contaminants by chemical action alone than their solvent counterparts. For this reason, aqueous cleaning must be supplemented by mechanical action and increased temperature. Where the contaminants to be removed are especially thick or insoluble, large amounts of mechanical action can be required. For delicate parts contaminated with thick grease or other similar compounds, the usefulness of aqueous cleaning systems can be significantly limited.

As part of the surveys and site visits conducted during the USACERL evaluation, users of automatic parts washers at military installations were questioned regarding their satisfaction with the cleaning ability of their automatic washers. They were also asked if significant pre-cleaning (steaming or scraping parts, brushing with solvent, etc.) was necessary to ensure that parts get clean. The majority of users ( 83 percent) reported being satisfied with the cleaning effectiveness of the automatic washers. Roughly half of all users report performing some type of pre-cleaning (i.e., scraping, steaming, etc.). However, this was generally done only if the parts were very dirty, and would probably be done with any type of parts cleaning, solvent or otherwise.

From 1994 to 1995, the Fuels and Lubricants Division of the Mobility Technology Center at Fort Belvoir conducted a study to determine requirements and constraints for a general purpose cleaning solvent that would replace P-D680, Dry cleaning and Degreasing Solvent, and still meet military needs. Commercial solvents, including aqueous cleaners, were tested in the laboratory 
to determine their conformance with needed requirements. One aspect of testing performed during this evaluation was determining the solvency of the individual cleaners. To do this, a simple soil test procedure was developed using an ultrasonic cleaner. Automatic parts washers were not tested, only the aqueous cleaners themselves. Test results showed that aqueous-based solvents did not effectively remove grease and soil (Rhee, Velez, and Von Bernewitz 1995).

It is reasonable to assume that the discrepancy between the study conducted at Fort Belvoir and the user evaluation performed by USACERL, was the result of the direct spray nozzles and increased temperatures that automatic parts washers add to the cleaning process. The 1995 Fort Belvoir study looked only at aqueous cleaners, not at the total parts washer. The addition of the mechanical action and hot water allows for greater cleaning capabilities than the use of aqueous cleaners alone.

\section{Rusting}

Another important parameter to consider when evaluating a solvent alternative is corrosion protection. Traditional petroleum solvents provide excellent protection on the surface of metal parts. This property is essential for military part cleaning applications to prevent damage and ensure equipment longevity.

The 1995 Fort Belvoir study referenced above included an assessment of corrosion properties of alternative solvents, including water-based solvents. The results of laboratory testing, both copper and steel corrosion tests (ASTM D 130 method), showed that most aqueous based cleaners, used alone, produced severe corrosion problems.

However, users questioned as part of the USACERL evaluation report very few corrosion problems when using aqueous cleaners in automatic parts washers. Only 38 percent of the users reported any rust problem, and in each case, that was very minor surface rusting. Because they are used in conjunction with hot water, the aqueous cleaners used in automatic washers do not appear to cause a significant corrosion problem. The high water temperatures result in high evaporation rates, causing most parts to dry immediately when the door of the washer is opened. One installation reported rust on parts that had remained in the washer overnight, probably due to cooling and condensation and water remaining on the parts. Those installations where parts are oiled or greased immediately after removal from the washer, or where parts are dried manually, report no rusting problems. 


\section{Part Damage}

Alkaline cleaners will etch aluminum, aluminum alloys, and zinc. Strong alkaline cleaners will tarnish copper alloys, remove zinc from brass, and attack solder. Solutions with a high $\mathrm{pH}$ can damage laminates and coatings and remove ink markings on components. High $\mathrm{pH}$ solutions can also dissolve tin and lead and attack solder joints (Nation Defense Center for Environmental Excellence 1994).

By their nature, aqueous cleaning solutions have high $\mathrm{pH}$ values and may adversely affect certain types of mechanical parts. Therefore, use of aqueous cleaners should be carefully considered for parts made of softer, more malleable, metals, or those with sensitive seals or other sensitive areas. All applicable technical manuals, military specifications, and manufacturer's literature should be carefully consulted to verify requirements for solvent substitutions.

Military specification, MIL-C-29602, dated 28 February 1995, was developed and published to provide cleaning compounds safe to use in aqueous parts washer for cleaning aircraft components. The specification ensures that compounds are effectively evaluated to ensure they do not damage aerospace equipment. The specification is approved for use by all U.S. Military services. 


\section{Installation, Operation, and Maintenance}

Installation

One important factor that must be considered when purchasing an automatic parts washer is the washer installation. Existing plumbing and electrical connections may not be adequate for washer installation and may have to be upgraded. One manufacturer of automatic parts washers, contacted by USACERL researchers, states that this is a very common problem when installing units at military maintenance shops. The minimum power required for their small units is $230 \mathrm{~V} /$ single-phase service and $230 \mathrm{~V} /$ three-phase service for their larger units. Most facilities are wired for standard 208V/three-phase service. Most equipment will operate within a range of voltage (i.e., the $208 \mathrm{~V}$ service can handle the $220 \mathrm{~V}$ machine requirement, but the washers with the $230 \mathrm{~V}$ requirement do not run well at the $208 \mathrm{~V}$ level. This particular manufacturer states that, if they are aware of the building's power service before purchase, they can rewire the machine to match the specific voltage. It is much more difficult to address this problem once the machine has arrived at the installation. Therefore, it is essential that installations identify their existing building utility connections. They can then either specify that washers purchased meet those requirements, or they can be prepared to include and allow for building modifications in the total project cost. Five parts washers installed at one installation required $\$ 150,000$ in building modifications for plumbing and electrical work.

\section{Operation and Maintenance}

O\&M is an important consideration when purchasing any equipment. Deciding on a solvent alternative is no exception. Types of O\&M for automatic parts washers range from daily checking of such things as water levels, oil skimmers, and filter bags, to the more periodic types of maintenance such as complete draindowns and cleanouts. 


\section{Operation and Daily Maintenance}

Proper operation is essential for any piece of equipment to ensure optimal results, minimal down time, and equipment life. However, if proper operation is difficult or time consuming, potential savings realized from using automatic equipment can be negated by increased labor costs.

Automatic parts washers are, in general, very easy to operate. Mechanics place parts in the washer, shut the door, and push a button to start the cleaning process. After the wash and rinse cycles are complete, clean parts are removed and the process is finished. However, several other factors may make the use of this equipment more difficult. These factors include:

1. The water level in the unit must be monitored to ensure that it does not drop below the operating level, destroying the heating element.

2. Because they operate at such high temperatures, these units can take several hours to heat up. This can be frustrating to the mechanic who needs to use the machine, but has to wait.

3. Hinges and fittings need to be greased frequently. Some installations do this on a daily basis.

4. Users may need to adjust the cleaner concentration to ensure optimum removal efficiency and allow for water quality variations (i.e., hard water will require more concentrated cleaner). They may find that a more concentrated cleaner is necessary to remove their typical soil levels. Or they may decide that the cleaner can be diluted and still adequately clean their parts, thereby saving money on cleaner purchases.

5. In many instances, automatic parts washers are installed in contractoroperated maintenance shops (Department of Logistics maintenance shops, for example). These shops generally have a relatively low employee turnover. Consequently, the people working in the shops where the washers are located have more experience dealing with any intricacies presented by any particular washer. This contrasts with those instances where automatic washers are operated by military personnel. Soldiers are frequently transferred in and out of units, a circumstance that can lessen continuity in operation. 


\section{Periodic Cleanouts}

Because the water in automatic washers is recycled, materials removed from the parts will accumulate in the wash water. Therefore, the washer must be periodically drained and completely cleaned. This requires shutting down the machine, draining and removing all water and sediment; and"cleaning all nozzles and any filter screens, bags, or other accessories. The washer is then refilled with clean water. This can be a time consuming and costly process. The washer is out of service during cleaning, possibly leaving mechanics without an alternate place to clean and resulting in unproductive "downtime." Sediment and water removed from the washer must be disposed of properly. This can be costly if the water and/or sludge is considered a hazardous waste. (See Chapter 5, "Environmental Concerns," for more information on this subject.) Users questioned as part of this evaluation report a wide range in the frequency of cleanouts. The worst case was reported by an installation that cleans out its washers once per week, while the least reported frequency was an installation where the washers had not been cleaned in 3 years. The average frequency reported, at installations where users are operating the washers on a frequent basis (i.e., almost daily), was approximately once every 6 months.

\section{Lessons Learned}

As part of this evaluation, users were asked about the types of daily maintenance performed and asked to provide suggestions or lessons learned for improving performance and decreasing maintenance. More than 50 percent of the users questioned during this evaluation report performing some type of maintenance on a daily basis. This includes greasing hinges and turntables, operating the oil skimmer, checking and cleaning nozzles, checking water levels, etc. Time estimates for this effort ranged from 5 to 30 minutes. Tips for enhancing performance and reducing high level maintenance were:

- Timers can be used to automatically turn the washer on. These can be set to begin before the work day starts, to ensure that the water is heated and the washers are ready for use. However, some installations with washers that have this option report that the timers have to be replaced quite frequently.

- Oil skimmers work best if run at night when water has had time to settle. This allows more oil to be removed from the water and may extend the length of time between complete cleanouts. 
- Filter bags and screens can lengthen the life of the wash water, decreasing the plugging of the water nozzles and decreasing the frequency of complete drain downs/cleanouts. These types of enhancements work best if cleaned on a very regular basis (i.e., daily for washers used extensively, or weekly for those used less frequently). This will also increase the useful life of the bag or screen.

- If there is no automatic make-up water option on the washer, water levels should be checked daily to ensure that they do not drop below the minimum operating level and damage the washer.

- One installation had problems with rust on the inside of the washer. They upgraded their washer to a stainless steel model. While the stainless steel is more expensive, they have greatly extended the life of their washer.

- The standard model of some types of parts washers comes with a drive wheel that rotates the turntable. If washers are used extensively, this wheel will wear quickly and may need to be replaced frequently. A chain driven turntable is a better option. 


\section{Environmental Concerns}

In the United States, regulations are becoming more stringent to reduce air pollution and the release of volatile organic compounds (VOCs) into the atmosphere. Historically, metal cleaning has been a large contributor of VOCs due to the high vapor pressure of most solvents. However, aqueous solvents contain very small amounts of VOCs due to their water content. This makes the substitution of aqueous cleaners for high VOC solvents an attractive alternative.

Aqueous cleaning generates a wastewater stream that requires treatment and discharge. In addition, many currently available aqueous cleaners contain nonbiodegradable components that make discharge to sewer systems or surface waters more problematic. Some cleaners that are biodegradable when new (unused), become nonbiodegradable once they have been used (and subsequently mixed with contaminants). The fact that the cleaners themselves are "biodegradable" can mislead users to believe they can also treat or handle the used cleaning solutions as a biodegradable substance-which is generally not the case.

There is a fallacy that "because your aqueous cleaner is biodegradable, the wastewater is safe. The fact is, once that cleaner hits the contaminant, it is no longer biodegradable and some treatment has to take place" (Schamisso 1992). Although aqueous cleaning compounds are initially nonhazardous and are often marketed as biodegradable, contaminants such as oil, grease, metals, and dirt accumulate during the cleaning process. Depending on the concentrations and local discharge limits, these contaminants may render spent water and cleaning solution unacceptable for discharge to a municipal sanitary sewer system or cause it to be hazardous because of toxicity. Cleaning compound chemicals may also be harmful to the environment, particularly if used in high concentration (Gedlinske 1997). Automatic parts washers do recycle the water. However, at some point, the water becomes too contaminated and cannot be recycled further. Then the washer must be cleaned and the waste materials disposed of properly.

Analytical data from parts washer waste streams at two installations was provided to USACERL researchers during the course of this study. Appendix B 
includes tables showing the results of this sample analysis. A summary of those results follows:

1. One washer at the first installation was located in an automotive shop and was used to degrease large engine parts. The sample from this washer was taken from the sediment/water mixture at the bottom of the tank. Analysis of this sample indicates cadmium at levels exceeding the Resource, Conservation, and Recovery Act (RCRA) limit.

2. This same installation has four parts washers in another building. This building supports a variety of missions including artillery repair, large caliber cannon proof testing (firing rounds through the cannon to subject it to typical and severe stresses), nondestructive testing, and painting. Analytical data from individual and composite samples taken from the four washers indicate that while the waste was not hazardous in every case, the water was still unsuitable for discharge to the sanitary sewer. The Total Petroleum Hydrocarbon (TPH) levels exceed $100 \mathrm{mg} / \mathrm{L}$. This is the discharge limit set by the installation for the individual industrial activities, located on that installation, that discharge to their wastewater treatment plant.

3. Another installation has automatic parts washers in three motor pools and several DOL facilities. Automotive parts are cleaned in all facilities with the exception of a small electrical shop. Analytical data from samples taken from these washers indicate that four out of the 12 samples taken indicate levels of lead and/or cadmium above the regulatory limit.

While some installations' parts washer waste streams have been found to contain hazardous contaminants above regulatory limits, other installations surveyed as part of this evaluation report that waste stream analysis has never exceeded regulatory limits. Of the installations surveyed, 70 percent have tested waste material from their washers. All of these have either found the waste to have contaminants exceeding regulatory limits at some point, or are disposing of the waste as an industrial or special waste. In those cases where no testing has been done, either the waste materials are collected and disposed of by a contractor, or the washer has only been at the facility for a brief period and the washer has not yet been cleaned out.

In a 1996 study performed by the Iowa Waste Reduction Center, the quality of discharge from automatic aqueous parts washers used by vehicle maintenance and metal manufacturing facilities was investigated. Grab wastewater samples were collected from 15 vehicle maintenance facilities and four metal 
manufacturing facilities and analyzed for commonly regulated pollutants. The $\mathrm{pH}$ was also measured. Results of this sample analysis were comparable to those from the two military installations described above. There was a wide range of contaminant concentrations, sometimes exceeding allowable discharge limits or requiring special permitting, monitoring, or reporting.

Results of this study also suggest that, because of the relationship between $\mathrm{pH}$ and the solubility of metals, monitoring and adjusting $\mathrm{pH}$ may prevent excessive heavy metal concentrations in aqueous cleaning solutions. This can potentially prevent the wash water from becoming a hazardous waste. Maintaining cleaning solution $\mathrm{pH}$ in the range of 10 to 10.5 may inhibit lead from becoming solubilized. However, this process of adjusting $\mathrm{pH}$ must be carefully monitored. Using strong acids poses safety concerns; the addition of too much acid can lower the $\mathrm{pH}$ to a more hazardous level. A pH less than or equal to 2 or greater than or equal to 12.5 causes a waste to become a hazardous waste due to corrosivity. The study suggests using vinegar for adjusting $\mathrm{pH}$ since it is relatively harmless, readily available, and inexpensive. $\mathrm{A} \mathrm{pH}$ monitor or $\mathrm{pH}$ indicator paper can be used to monitor adjustments. From the first installation listed above, $\mathrm{pH}$ values for samples taken ranged from 7.73 to 10.06 . Values within this range do not need to be adjusted.

Potential users of automatic parts washers should consider that, while aqueous cleaners may reduce volatile organic compound (VOC) emissions on the installation, they may also increase the hazardous waste stream. Installations should carefully consider the possible additional costs that may be incurred from waste stream analysis and hazardous waste disposal. 


\section{Conclusions and Recommendations}

Because of increasing concerns about the safety and environmental issues surrounding traditional solvents, many parts cleaning practices that once relied on high VOC, petroleum-based solvents are now being done with aqueous cleaning. The use of automatic aqueous parts washers is one of these alternatives. The results of this study show that users are generally satisfied with the performance of these washers and that the. washers are relatively low maintenance. However, the following should be considered:

1. When combined with spray nozzles and hot water, aqueous cleaning solutions provide adequate solvency. Most users were satisfied with the automatic parts washer cleaning capability. Some pre-cleaning may be required, however, if the parts are extremely dirty.

2. Users must consider the types of parts to be cleaned in any application before deciding on a solvent substitution. Automatic aqueous parts washers produce little corrosion and seldom damage parts, but if the parts to be cleaned have sensitive seals or are made of metals that will etch or pit easily, another alternative should be chosen.

3. Installations must specify electrical and plumbing requirements when ordering equipment. Lack of details may result in unexpected, expensive building modifications.

4. In general, automatic parts washers are easy to operate. However, low level maintenance is needed, sometimes on a daily basis. This can include monitoring water levels, greasing hinges, and adjusting cleaner concentration. Shops with low employee turnover may be better equipped to maintain the washers.

5. Periodic cleanouts are required as part of washer maintenance. These can be time consuming and sometimes costly, but generally only need be done once or twice per year. 
6. Sediment and/or wastewater removed from washers during cleanouts may be a hazardous waste and may require special handling for disposal. Even if not determined to be hazardous, special handling may be required due to high levels of oils and grease. The costs of this disposal should be taken into account when deciding on solvent replacement alternatives. Wastewater may exceed limits for discharge to sanitary sewer systems.

7. Keeping $\mathrm{pH}$ at acceptable levels (10 to 10.5) may decrease heavy metal solubilization, therefore possibly preventing the wastewater from becoming a hazardous waste. 


\section{References}

Adams, Mark, White Papers: Aqueous Parts Washers and Wastewater Evaporators (Hydro-Blast Inc., April 1997).

Adams, Mark, and M.J. Larson, "Evaporative Technology for Waste Stream Reduction in Aqueous Parts Washers," Diesel Progress Engines and Drives, vol 61, No. 2 (February 1995), p 57.

National Defense Center for Environmental Excellence, Aqueous Cleaning-Alternative Materials (May 1994).

"Conversion From Solvent to Hot Water Degreasing Reduces Annual Emission Fees for Job Shop," Modern Machine Shop, vol 63, No. 12 (May 1991), pp 126-129.

"Gaps in Aqueous Cleaning Research," Aqueous Cleaning Technology Review (Pacific Northwest Pollution Prevention Research Center, May 1996).

Gedlinske, Brian, "Aqueous Parts Washing and Pollutant Loadings," Pollution Prevention Review, (Spring 1997), pp 47-60.

Koelsch, James R., "Guilt-Free Parts Cleaning," Manufacturing Engineering, vol 114, No. 3 (March 1995), pp 81-87.

Menke, Dean M., et al., Demonstration of Alternative Cleaning Systems, EPA/600/R-95/120 (U.S. Environmental Protection Agency [USEPA], Washington DC, August 1995).

"ODS-Free Metal Cleaning Overview," Pollution Prevention Technical Library (Maintained by the Naval Facilities Engineering Service Center [NFESC], March 1996).

Ohio Environmental Protection Agency (EPA), Pollution Prevention Alternatives for Ozone LayerDepleting Solvents in Metals Parts Cleaning, Fact Sheet Number 8 (Ohio EPA, February 1993).

Schamisso, Andrew, "Alternatives to Vapor Degreasing," American Machinist, vol 136, No. 10 (October 1992), pp 65-67.

"Technical Issues and Aqueous Cleaning Systems," Aqueous Cleaning Technology Review (Pacific Northwest Pollution Prevention Research Center, May 1996).

"Two Basic Approaches to Aqueous Cleaning-Batch Process and Continuous Process," Wisconsin Department of Natural Resources (WDNR) Fact Sheet (WDNR, April 1997).

Rhee, In-Sik, Carlos Velez, and Karen Von Bernewitz, "Replacement of P-D-680 Solvents for General Maintenance of DOD Equipment," Interim Report (September 1995). 


\section{Appendix A: Automatic Parts Washer Manufacturers}

\begin{tabular}{|c|c|c|}
\hline Manufacturer & Address & Phone/Fax \\
\hline ADF Systems Ltd. & $\begin{array}{l}\text { P.O. Box } 278 \\
\text { Humboldt, IA } 50548\end{array}$ & $\begin{array}{l}\text { P.h: }(515) 332-5400 \\
\text { F: } \quad(515) 332-4475\end{array}$ \\
\hline American Metal Wash - & $\begin{array}{l}360 \text { Euclid Ave. } \\
\text { Canonsburg, PA } 15317\end{array}$ & $\begin{array}{l}\text { Ph: }(412) 746-4203 \\
F: \quad(412) 756-5738\end{array}$ \\
\hline Better Engineering Mfg, Inc. & $\begin{array}{l}7101 \text { Bel Air rd. } \\
\text { Baltimore, MD 21206 }\end{array}$ & Ph: $(800) 229-3380$ \\
\hline Bowden Industries & $\begin{array}{l}1004 \text { Oster Drive, NW } \\
\text { Huntsville, AL } 35816\end{array}$ & Ph: (800) KLEENER \\
\hline California Steam, Inc. & $\begin{array}{l}\text { 4300 82nd St. } \\
\text { Suite } 1 \\
\text { Sacramento, CA } 95826\end{array}$ & $\begin{array}{l}\text { Ph: (800) 432-7999 } \\
\text { F: (916) 454-9774 } \\
\text { Email: calsteam@rcip.com } \\
\text { Web: http://rcip.com/calsteam/ }\end{array}$ \\
\hline Cleanomat & $\begin{array}{l}664 \text { Medelssohn Ave. } \\
\text { Golden Valley, MN } 55427\end{array}$ & Ph: $(612) 591-9388$ \\
\hline $\begin{array}{l}\text { Cowart Custom Machines, Inc. } \\
\text { Dept. } 10\end{array}$ & $\begin{array}{l}\text { P.O. Box } 3767 \\
\text { Valdosta, GA } 31604-3767\end{array}$ & $\begin{array}{l}\text { Ph: (800) 548-7757 } \\
\text { F: (912) 245-8438 } \\
\text { Web: http://www.cowart-inc.com }\end{array}$ \\
\hline F.M.T., Inc. & $\begin{array}{l}1950 \text { Industrial Dr. } \\
\text { Findlay, } \mathrm{OH} 45840\end{array}$ & $\begin{array}{l}\text { Ph: (412) } 422-0768 \\
F:(412) 422-0072\end{array}$ \\
\hline Seln & BOS & 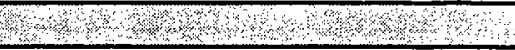 \\
\hline GraPar Corp. & $\begin{array}{l}25135 \text { Flanders } \\
\text { Warren, Ml } 48089\end{array}$ & $\begin{array}{l}\text { Ph: }(810) 773-5250 \\
F: \quad(810) 773-8330\end{array}$ \\
\hline 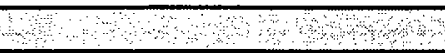 & 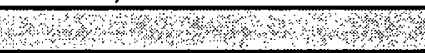 & 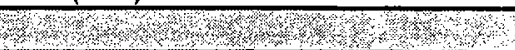 \\
\hline Graymills Corp. & $\begin{array}{l}3705 \text { N. Lincoln Ave. } \\
\text { Chicago, IL 60613-3594 }\end{array}$ & $\begin{array}{l}\text { Ph: }(888) \text { 41-PUMPS } \\
\text { F: }(800) 478-8673\end{array}$ \\
\hline कित & Hof & 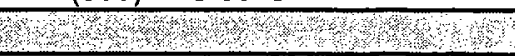 \\
\hline Hydro-Blast, Inc. & $\begin{array}{l}6917 \text { N.E. 39th Court } \\
\text { Vancouver, WA } 98661-1355 \\
.\end{array}$ & $\begin{array}{l}\text { Ph: }(800) 332-1590 \\
\text { F: (360) 696-5948 } \\
\text { Web: http://www.adpub.com/hydro- } \\
\text { blast/ }\end{array}$ \\
\hline & cosol, & 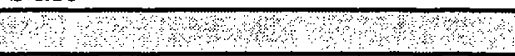 \\
\hline INTERCONT Products & $\begin{array}{l}1719 \text { W. Mt. Vernon } \\
\text { Springfield, MO } 65802\end{array}$ & Ph: $(800) 344-5191$ \\
\hline
\end{tabular}




\begin{tabular}{|c|c|c|}
\hline Manufacturer & Address & Phone/Fax \\
\hline Kleerflo, Inc. & $\begin{array}{l}\text { 15151-M Technology Dr. } \\
\text { Eden Prairie, MN } 55344\end{array}$ & $\begin{array}{l}\text { Ph: }(800) 261-2556 \\
F: \quad(800) 690-3909\end{array}$ \\
\hline \multirow{2}{*}{ Kleiber \& Schulz, Inc. } & 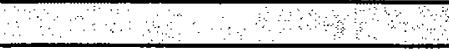 & 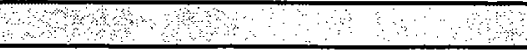 \\
\hline & $\begin{array}{l}\text { 2017-T New Highway } \\
\text { Farmingdale, NY } 11735\end{array}$ & $\begin{array}{l}\text { Ph: (888) 871-9677 } \\
\text { F: (516) 293-1856 } \\
\text { Email: kswetblast@earthlink.net } \\
\text { Web: } \\
\text { http://www.kswetblast.thomasregist } \\
\text { er.com }\end{array}$ \\
\hline \multicolumn{3}{|c|}{$\therefore$, } \\
\hline Landa, Inc. & $\begin{array}{l}13705 \text { N.E. Airport Way } \\
\text { Portland, OR } 97230\end{array}$ & $\begin{array}{l}\text { Ph: (800) 645-2632 } \\
\text { F: } \quad(800) 535-9164 \\
\text { Email: landa@landa-inc.com } \\
\text { Web: http://www.landa-inc.com } \\
\end{array}$ \\
\hline \multicolumn{3}{|c|}{ 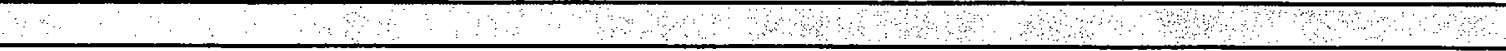 } \\
\hline Lewis Corp. & $\begin{array}{l}102 \text { Willenbrock Rd. } \\
\text { Oxford, CO } 06483\end{array}$ & Ph: (203) 264-3100 \\
\hline \multicolumn{3}{|c|}{ 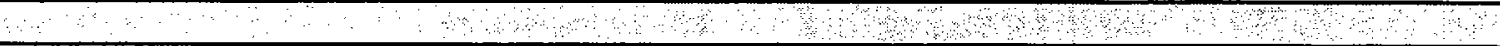 } \\
\hline $\begin{array}{l}\text { ManGill Chemical } \\
\text { Mangus Division }\end{array}$ & $\begin{array}{l}7255 \text { Division St. } \\
\text { Oakwood Village, } \mathrm{OH} 44146\end{array}$ & Ph: $(800) 627-6422$ \\
\hline \multirow{2}{*}{ Proceco LTD. } & 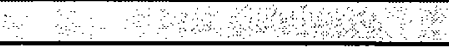 & $\therefore \mathrm{s}+\mathrm{QH}$ \\
\hline & $\begin{array}{l}14790 \text { St. Augustine Rd. } \\
\text { Jacksonville, FL } 32258-4407\end{array}$ & $\begin{array}{l}\text { Ph: (800) 978-6677 } \\
\text { F: (514) 254-6922 } \\
\text { Email: cleaning@proceco.com } \\
\text { Web: http://www.proceco.com }\end{array}$ \\
\hline \multicolumn{3}{|c|}{ a } \\
\hline RAMCO & & $\begin{array}{l}\text { Ph: }(800) 553-3650 \\
\text { F: (908) } 687-0653 \\
\text { Web: http://www.ramkleen.com }\end{array}$ \\
\hline \multicolumn{3}{|c|}{ 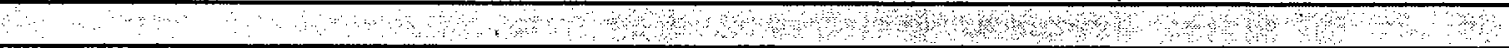 } \\
\hline \multirow{2}{*}{\multicolumn{3}{|c|}{$\begin{array}{lll}\text { Roto-Jet of America Co., Inc. } & \begin{array}{l}\text { 2819 San Fernando Blvd. } \\
\text { Burbank, CA 91504 }\end{array} & \begin{array}{l}\text { Ph: (818) 841-1520 } \\
\text { F: (818) 841-6448 } \\
\text { Web: http://www.roto-jetoa.com }\end{array}\end{array}$}} \\
\hline & & \\
\hline Stoelting, Inc. & $\begin{array}{l}502 \text { Highway } 67 \\
\text { Kiel, WI } 53042 \\
\end{array}$ & Ph: (414) 894-7029 \\
\hline \multicolumn{3}{|c|}{ S } \\
\hline $\begin{array}{l}\text { Vibron Division } \\
\text { Burgess \& Associates } \\
\end{array}$ & $\begin{array}{l}33660 \text { Pin Oak Parkway } \\
\text { Avon Lake, OH } 44012\end{array}$ & Ph: $(800) 322-2283$ \\
\hline
\end{tabular}




\section{Appendix B: Sample Analyses of Parts Washer Waste Streams}

\begin{tabular}{l}
$\begin{array}{l}\text { Installation A - Bldg } 338 \text { - Sample Analysis } \\
\text { (all units are mg/L) }\end{array}$ \\
\hline Sample ID \\
\hline
\end{tabular}

\begin{tabular}{|c|c|c|c|c|c|c|c|c|c|c|c|}
\hline \multicolumn{12}{|c|}{$\begin{array}{l}\text { Installation } \mathrm{A} \text { - Bldg } 525 \text { - Sample Analysis } \\
\text { (all units are } \mathrm{mg} / \mathrm{L} \text { ) }\end{array}$} \\
\hline Sample ID & Date & As & $\mathrm{Ba}$ & Cd & $\mathrm{Cr}$ & $\mathrm{Pb}$ & $\mathrm{Hg}$ & Se & $\mathrm{Ag}$ & $\mathrm{pH}$ & TPH \\
\hline$W-1$ & 28-Feb-94 & $B D L$ & 3.25 & 0.908 & 9.02 & 3.39 & 0.00158 & $\mathrm{BDL}$ & BDL & 7.91 & 43.9 \\
\hline$w-2$ & 22-Feb-94 & 2.68 & 8.63 & 0.783 & 3.7 & 3.59 & 0.00116 & BDL & 0.678 & 7.73 & 30.2 \\
\hline$w-3$ & 15-Feb-94 & BDL & 0.902 & 0.66 & 0.76 & 1.58 & BDL & BDL & BDL & NA & NA \\
\hline$W-4$ & 30-Mar-94 & BDL & 4.71 & 1.11 & 50.7 & 7.23 & 0.0026 & $\mathrm{BDL}$ & $B D L$ & NA & NA \\
\hline$C-1$ & 2-Jul-97 & NA & NA & 0.07 & 0.33 & 0.05 & 0.0017 & NA & $<0.03$ & 9.3 & 1740 \\
\hline$C-2$ & 2-Jul-97 & NA & NA & 0.09 & 0.63 & 0.27 & 0.002 & NA & $<0.03$ & 10.06 & 261 \\
\hline$C-3$ & 2-Jul-97 & NA & NA & 0.37 & 0.02 & 0.09 & 0.0019 & NA & $<0.03$ & 8.10 & 129 \\
\hline$C-6$ & 31-Oct-95 & $<1.0$ & 0.18 & $<0.20$ & 1.50 & 1.40 & 0.0033 & 0.13 & 0.14 & 9.64 & 283 \\
\hline$C-7$ & 15-May-95 & BDL & 1.6 & 0.13 & 1.6 & 0.17 & $B D L$ & $B D L$ & BDL & NA. & 5600 \\
\hline \multicolumn{2}{|c|}{ Regulatory Limit* } & 5.0 & 100.0 & 1.0 & 5.0 & 5.0 & 0.2 & 1.0 & 5.0 & & \\
\hline NA = not available & $\begin{array}{l}\text { detection lim } \\
\text { lable } \\
\text { ister, Vol. } 55\end{array}$ & 61 & ured & 1 & 1) & & 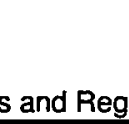 & tin & & & \\
\hline
\end{tabular}




\begin{tabular}{|c|c|c|c|c|c|c|c|c|c|}
\hline \multicolumn{10}{|c|}{$\begin{array}{l}\text { Installation } B \text { - Sample Analysis } \\
\text { (all units are } \mathrm{mg} / \mathrm{L} \text { ) }\end{array}$} \\
\hline Sample ID & Date & As & Ba & $\mathrm{Co}$ & $\mathrm{Cr}$ & $\mathrm{Pb}$ & $\mathrm{Hg}$ & Se & $\mathrm{Ag}$ \\
\hline Bldg 1411 - Small & 3-Aug-95 & 0.12 & 1.64 & 0.7 & 1.74 & 1.68 & BDL & 0.019 & $B D L$ \\
\hline Bldg 1411 - Large & 3-Aug-95 & 0.33 & 0.77 & 0.062 & 2.73 & 0.05 & $\mathrm{BDL}$ & 0.076 & $B D L$ \\
\hline Bldg 1411 - Large Sludge & 3-Aug-95 & 0.14 & 2.49 & 1.45 & 0.97 & 22 & BDL & 0.037 & 0.19 \\
\hline Bldg 1411 - Main Auto Shop & 3-Aug-95 & 0.036 & 3.87 & 2.01 & 1.45 & 2.39 & $\mathrm{BDL}$ & $\mathrm{BDL}$ & 0.034 \\
\hline Bldg 2750 - Small & 3-Aug-95 & 0.017 & 0.33 & 0.022 & 1.12 & 0.087 & $\mathrm{BDL}$ & $\mathrm{BDL}$ & $\mathrm{BDL}$ \\
\hline Bldg 2750 - Large & 3-Aug-95 & 0.022 & 0.67 & 0.6 & 0.23 & 8.79 & $\mathrm{BDL}$ & 0.033 & 0.35 \\
\hline Bldg 2413 - Hangar & 3-Aug-95 & 0.054 & 0.024 & 0.45 & 0.5 & 0.23 & 0.002 & 0.15 & 2.16 \\
\hline Bldg 1406 - Large & 3-Aug-95 & 0.11 & 17.6 & 1.98 & 2.49 & 16.5 & $\mathrm{BDL}$ & 0.063 & 0.091 \\
\hline Bldg 1406 - Small & 3-Aug-95 & 0.034 & 1.47 & 0.017 & 2.32 & 2.4 & $\mathrm{BDL}$ & 0.022 & 0.006 \\
\hline Bldg 2702 & 3-Aug-95 & 0.01 & 1.33 & 0.52 & 0.032 & 0.11 & $\mathrm{BDL}$ & 0.011 & $\mathrm{BDL}$ \\
\hline Regulatory Limit* & & 5.0 & 100.0 & 1.0 & 5.0 & 5.0 & 0.2 & 1.0 & 5.0 \\
\hline
\end{tabular}

